\title{
COOPERATIVE PLAY UNTUK MENURUNKAN PERILAKU SIBLING RIVALRY
}

\author{
PADA ANAK \\ Julhan Efendi Lubis \\ UIN Syarif Hidayatullah Jakarta, Indonesia \\ E-mail: fendiabay@gmail.com
}

\begin{abstract}
This method aims to find out and understand more deeply how cooperative play can reduce sibling rivalry behavior in children. The approach taken is to use pre-post test interventions. The subjects in this study were selected using purposive sampling techniques and data collection techniques, which were carried out by the method of observation and in-depth interviews. Topics in this study amounted to two people aged five years and four years. The results showed that cooperative play could reduce sibling rivalry behavior in children.
\end{abstract}

Keywords: child, cooperative play, sibling rivalry

Abstrak. Metode ini bertujuan untuk mengetahui dan memahami lebih mendalam mengenai bagaimana cooperative play untuk menurunkan perilaku sibling rivalry pada anak. Pendekatan yang dilakukan adalah dengan menggunan intervensi pre post test. Subjek dalam penelitian ini dipilih dengan teknik pusposive sampling dan Teknik pengumpulan data yang dilakukan dengan metode oberservasi dan wawancara mendalam. Subjek dalam penelitian ini berjumlah dua orang yang berusia 5 tahun dan 4 tahun. Hasil penelitian menunjukkan bahwa cooperative play mampu menurunkan perilaku sibling rivalry pada anak.

Kata Kunci: Anak, Cooperative Play, Sibling Rivalry

Permalink/DOI: https://doi.org/10.15408/harkat.v15i2.13467 


\section{Pendahuluan}

Kasus kelompok ini berada dalam setting keluarga yakni dua orang kakak adik saudara sekandung yang memiliki jenis kelamin yang berbeda. Fokus kasus yaitu adanya perilaku salah satu dari saudara kandung yang seringkali melakukan tindakan fisik terhadap adiknya. Tindakan fisik masuk dalam kategori kekerasan fisik seperti memukul, mencubit, mendorong. Sementara adiknya sering merespon perlakuan abangnya dengan menangis meskipun terkadang hanya disebabkan hal kecil seperti tidak diajak bermain oleh abangnya.

Pada kasus ini, peneliti sudah melakukan pengamatan observasi yang cukup lama terhadap kedua anak saudara kandung ini. Kakaknya berjenis kelamin laki-laki berusia 4 tahun 11 bulan tahun sedang duduk di bangku TK A, sementara adiknya berjenis kelamin perempuan berusia 3 tahun 11 bulan. Jarak usia diantara keduanya tergolong sangat dekat. Berdasarkan hasil wawancara dengan Ibu subjek partisipan, saat ibunya masih dalam proses memberikan ASI terhadap kakak, tanpa direncanakan ternyata ibunya sudah mengandung adiknya yang sudah berusia 3 bulan. Hal ini diketahui saat ibu ingin memasang $\mathrm{KB}$ di poli kandungan di sebuah rumah sakit swasta di wilayah Tangerang Selatan. Kenyataan tersebut sempat membuat ibunya terkejut dan merasa was-was serta kebingungan bagaimana kedepannya. Namun setelah dijalani, Ibunya maupun ayahnya mampu menjalani semuanya.

Hal tersebut berlangsung hingga Adiknya lahir saat kakak berusia 1 tahun. Setelah kelahiran adiknya, saat ibu dan adik bayi pulang ke rumah. Kakaknya menangis cukup lama melihat ibunya datang dengan bayi baru sementara kakak dan ibunya sudah terpisah selama dua hari karena ibunya harus menjalani proses persalinan. Tentu hal tersebut membuat ibunya sedih. Namun, sejak saat itu baik ibunya maupun ayahnya selalu mengutamakan perhatian ke kakaknya terlebih dahulu baru kemudian terhadap adiknya. Hal ini dilakukan dengan harapan agar kakak tetap merasa nyaman dan diperhatikan meskipun dengan kehadiran adiknya yang baru lahir.

Mengutamakan memberikan perhatian terhadap kakak sejak bayi tampaknya masih membuat kakak belum terlihat puas. Kakak seringkali membuat adiknya menangis. Hal ini sudah terlihat sejak usia mereka masih balita, Kakak berusia 2 tahun dan adiknya berusia 1 tahun. Perilaku yang saat itu sering diperlihatkan adalah perilaku kakak yang sering mendorong adiknya, memukul adeknya dan mudah sekali menangis. Sementara adiknya lebih sering meresponnya dengan menangis dibandingkan membalas perlakuan fisik kakaknya. Hal ini masih terjadi hingga usia mereka sekarang. Kakak masih sering memberikan serangan fisik kepada adik seperti memukul, mencubit, merebut mainan yang sedang dimainkan adiknya, serta sering mengatur adiknya agar menuruti perintah kakak. Sementara adiknya sering merespon dengan menangis apalagi saat ibunya sudah berada di rumah. Selain itu, adik sangat jarang melakukan pembalasan terhadap kakaknya.

Hasil wawancara yang dilakukan terhadap pengasuhnya, saat ibunya tidak berada di Rumah, kakaknya memang beberapa kali melakukan hal-hal yang sering membuat adiknya menangis terkadang penyebabnya adalah dikarenakan hal-hal kecil seperti adiknya tidak merespon ucapannya kemudian kakak akan memukul adiknya dan terkadang mencubit adiknya. Namun intensitas akan lebih sering jika ayah dan ibunya sudah berada dirumah. Kakaknya akan melakukan hal-hal yang membuat Ibunya mengharuskan untuk selalu bersamanya. Dalam situasi seperti ini, adeknya juga akan lebih rewel dibandingkan saat ibunya tidak berada di rumah. Selain itu, saat waktunya tidur, Ibu akan berada ditengah-tengah diantara keduanya. Karena jika ibunya tidur miring ke kiri ke arah kakaknya maka adiknya akan 
menangis dan memintanya mengarah kekanan, begitu juga dengan kakaknya juga melakukan hal yang sama, jika ibunya menghadap kekanan kearah adiknya maka kakaknya pun akan protes dan meminta ibunya menghadap ia. Maka, solusi yang diberikan ibunya adalah tidur dengan posisi badan telentang sembari memeluk keduanya disisi kanan dan kiri tangan ibunya.

Sebetulnya kakak mempunyai sifat penyayang, hal ini dapat diketahui dari hasil wawancara terhadap gurunya saat masih di Daycare dan sekarang dikelas TK A, bahwa sikap kakak saat berada di sekolah sangat toleransi terhadap temannya dan sangat baik terhadap temannya yang lebih kecil. Kakak akan lebih mengutamakan temannya, sering merangkul temannya yang lebih kecil darinya. Hampir tidak ada masalah interpersonal dengan temantemannya di Sekolah. Informasi tersebut diperkuat dengan kesesuaian dari hasil pengamatan observasi peneliti saat berada di Sekolahnya.

Sikap kakak terhadap teman sepermainnya di rumah juga lebih toleransi. Sama dengan perlakuannya dengan teman di Sekolahnya. Kakak akan lebih mengutamakan teman bermainnya, Ia akan dengan mudah meminjamkan maupun memberikan mainan kepada temannya dibandingkan harus memberikan mainan tersebut kepada adiknya.

Selain hal-hal di atas, dalam keseharian berdasarkan pengamatan observasi, terkadang kakaknya terlihat enggan mengabulkan permintaan ibunya saat ibunya meminta tolong, butuh instruksi beberapa kali dan seringkali kakak justru menyuruh adeknya yang mengerjakan.

\section{Diagnosis}

Kakak terlihat menganggap adiknya sebagai ancaman dan saingan. Sering membuat adiknya menangis, tidak mau berbagi dengan adiknya, sering melakukan aktivitas fisik seperti memukul, mencubit, dan mendorong. Tidak mengizinkan ibunya tidur menghadap adiknya, dan begitu juga sebaliknya adiknya juga tidak mengizinkan ibunya menghadap ke arah abangnya. Selain itu sikap adiknya terhadap kakak juga lebih sering merespon dengan menangis, dan terkadang juga dikarenakan hal kecil seperti kakaknya tidak mau berbagi makanan untuknya meskipun makanan yang sudah dibagikan sudah sama porsinya. Selain itu, kedua saudara kandung ini merasa takut tidak diperhatikan ayah dan ibunya serta adanya kecenderungan rasa cemburu. Kedua anak ini memiliki kecendrungan perilaku sibling rivalry.

Sibling rivalry adalah kecemburuan, persaingan dan pertengkaran antara saudara lakilaki dan saudara perempuan, hal ini terjadi pada semua orang tua yang mempunyai dua anak atau lebih (Kail, 2005 dalam Safithry, 2016). Sibling rivalry terjadi jika anak merasa mulai kehilangan kasih sayang dari orang tua dan merasa bahwa saudara kandung adalah saingan dalam mendapatkan perhatian dan kasih sayang dari orang tua (Setiawati, 2005 dalam Safithry, 2016).

Sibling Rivalry adalah persaingan, permusuhan, dan perilaku negatif di antara saudara-saudara dan saudara perempuan (Maiorano, 2010). Sibling rivalry menurut Shaffer (2014) adalah semangat kompetisi, kecemburuan atau kemarahan saudara kandung yang dimulai sejak lahirnya adik dalam keluarga. Bee dan Boyd menjelaskan bahwa sibling rivalry adalah tipe hubungan saudara kandung yang memiliki elemen yang sama dengan critical relationship dengan tingkat yang rendah dalam dukungan dan pertemanan. Rivalrous atau critical relationship biasanya terjadi pada pasangan kakak adik dengan rentang usia yang dekat (kurang dari 4 tahun) dan sangat tinggi pada pasangan kakak beradik dengan jenis kelaminnya sama. 


\section{Aspek Sibling rivalry}

Menurut Shaffer (2014) ada 3 aspek sibling rivalry, yaitu :

- Perilaku agresif atau resentment (kekesalan, kemarahan, kebencian)

- Kompetisi atau semangat untuk bermain (tidak mau mengalah)

- Perasaan iri dan cemburu dengan mencari perhatian

\section{Penyebab Sibling Rivalry}

Moser, Jones, Zaorski, dan Mirsalimi (2005) mempelajari kecemburuan, iri hati, rasa bersalah, dan kebencian antara saudara kandung dan menemukan bahwa persaingan bermula terutama dari persaingan atas perhatian dari Caretaker. Ada anak lain yang ditambahkan ke keluarga, kasih sayang ibu harus dibagi antara banyak keturunan yang menyebabkan konflik. Anak satu-satunya menjadi anak yang lebih tua dan bergerak dari posisi sentral yang menarik ke salah satu yang membutuhkan berbagi (Neubauer, 1983). Beberapa melihat sifat kompetitif saudara kandung menjadi hasil negatif dari persaingan saudara kandung. Namun, persaingan antar saudara dapat memiliki konsekuensi positif karena anak-anak sering belajar keterampilan dari saudara kandung seperti berbagi dan berkompromi. (Maiorano, 2010).

Perhatian dari orang tua bukan satusatunya alasan untuk konflik saudara. Masalah paling umum untuk saudara kandung adalah berbagi barang pribadi untuk yang lebih tua dan adik-adik (McGuire, Manke, Eftekhari, \& Dunn, 2000). Perilaku orang tua itu jarang disebut sebagai sumber konflik. Ini bisa menunjukkan bahwa persaingan antar saudara tidak selalu disebabkan dan dipengaruhi oleh perhatian orangtua tetapi sesama saudara memiliki masalah sendiri yang terpisah dari yang melibatkan orang tua mereka (Maiorano, 2010).

Beberapa faktor lain yang mungkin mempengaruhi konflik saudara adalah usia, gender, dan kekerabatan biologis. Misalnya, Erel, Margolin, dan John (1998) mempelajari 73 pasang saudara kandung antara usia 3 dan 6 tahun untuk menilai pentingnya perbedaan usia dalam konflik saudara. Saudara kandung itu direkam dalam pengaturan laboratorium sementara ibu mengisi kuesioner tentang hubungan perkawinannya dan hubungannya dengan anak-anaknya. Hasilnya menunjukkan bahwa ada lebih banyak perilaku negatif dari saudara kandung yang lebih tua yang diarahkan pada adik-adik. Meskipun rentang usia yang relatif kecil, semakin besar ruang di antara saudara kandung, semakin besar kehangatan yang diberikan saudara muda itu kepada keluarga saudara yang lebih tua (Maiorano, 2010).

Perbedaan jenis kelamin juga memainkan peran penting dalam hubungan sibling atau saudara. Martin dan Ross (2005) berhipotesis bahwa saudara laki-laki akan lebih terlibat dalam agresi fisik dibandingkan dengan saudara perempuan. Hasilnya menemukan bahwa saudara lelaki terlibat dalam lebih banyak agresifitas fisik dan verbal dibandingkan anak perempuan tetapi bentuk agresi yang paling parah hanya ditemukan ketika anak-anak berusia 2/2 tahun. Namun, beberapa bentuk agresi fisik dan verbal terus digunakan oleh anak laki-laki saat mereka bertambah tua. Juga dilaporkan bahwa saudara kandung yang lebih tua, tanpa memandang jenis kelamin, terlibat dalam agresi fisik yang kurang intens yang ditujukan pada seorang saudara perempuan, sementara adik-adik kandungnya lebih sering menyerang ketika konflik terjadi dengan saudara laki-laki yang lebih tua (Maiorano, 2010).

\section{Dimensi Sibling Rivalry}

Aspek utama dalam kualitas sibling relationship yaitu dimensi yang terdiri dari Warmth, Hostility dan Rivalry (Dunn, 1993; Furman \& Buhrmester, 1985). 
Dimensi pertama warmth berkaitan dengan perilaku dukungan, bantuan, berbagi, dan kekaguman di antara saudara kandung. Hostility adalah ukuran frekuensi perselisihan, di mana saudara kandung bertengkar, menggoda dan saling memancing. Rivalry persepsi bahwa anak-anak memiliki penanganan yang berbeda dari orang tua mereka, terutama dalam hal kasih sayang dan perhatian yang diterima dibandingkan dengan saudara kandung mereka. (Boer, et. al, 1997).

\section{Metode}

Peneliti melakukan intervensi dengan metode cooperative play dengan harapan dapat meningkatkan hubungan baik antar saudara kandung. Alasan peneliti memilih metode ini karena dapat diterapkan kepada anak dan juga dapat dilakukan dengan waktu yang singkat. Selain itu metode intervensi ini juga menggunakan lembar observasi dalam mengobservasi selama kegiatan Cooperative Play yang dibantu oleh dua observer. Lembar kuesioner juga diberikan kepada ayah atau Ibu dari kedua bersaudara ini.

\section{Teori Metode Intervensi}

Cooperative play adalah suatu permainan dalam bentuk kelompok yang terorganisir untuk mencapai tujuan tertentu, misal untuk membuat sesuatu, bermain permainan formal, atau mendramatisir situasi, satu atau dua anak mengontrol anggota kelompok dan mengarahkan aktivitas. Permainan pembagian kerja tiap anak mengambil peran yang berbeda dan saling melengkapi usaha yang lain. (Parten, 2008 dalam Margaretha, 2016).

Penelitian permainan kooperatif membedakan antara kompetitif, kooperatif, dan mode kolaborasi bermain game, mengacu pada tujuan dan insentif yang dirancang dalam sistem. Permainan kooperatif situasi model di mana peserta memiliki minat bekerja sama, tetapi jangan memaksakan kerja sama (mis. Strategi digunakan dalam permainan). Dalam permainan kolaboratif, fungsi pemain sebagai tim dan berbagi hasil dan hasil (Spasojevic et. al, 2012).

Selain itu, Wong (2008) menyebutkan bahwa cooperative play merupakan permainan yang dilakukan dengan langkah kerjasama yang bersifat teratur dan anak bermain dalam kelompok bersama dengan dengan yang lainnya. Anak-anak berdiskusi dan merencanakan aktivitas yang akan dilakukan untuk mencapai tujuan tertentu. Karakteristik permainan ini adalah permainan dilakukan oleh minimal dua orang anak dan pada saat bermain anak akan berbicara, meminjamkan mainan, membiarkan mainannya untuk tujuan yang ingin dicapai bersama. Anak saling mengikuti aturan yang mereka anggap baik.

Berdasarkan dari dimensi yang sudah dijelaskan di atas, maka alat ukur dari sibling rivalry yaitu terdiri dari warmth dimana itemnya adalah yang berkaitan dengan perilaku dukungan, bantuan, berbagi, dan kekaguman di antara saudara kandung. Skala Hostility adalah ukuran frekuensi perselisihan, di mana saudara kandung bertengkar, menggoda dan saling memancing. Dimensi ketiga yaitu Rivalry mengukur persepsi bahwa anak-anak memiliki penanganan yang berbeda dari orang tua mereka, terutama dalam hal kasih sayang dan perhatian yang diterima dibandingkan dengan saudara kandung mereka. (Boer, et. al, 1997).

\section{Karakteristik Subjek}

Subjek dalam penelitian ini adalah kakak dengan jenis kelamin laki-laki yang berusia 5 tahun dan sudah duduk di bangku sekolah TK A. Proses intervensi sendiri melibatkan adik kandungnya yang berjenis kelamin perempuan dengan usia 4 tahun. 


\section{Desain Penelitian}

Desain yang digunakan dalam penelitian ini adalah menggunakan One Group PretestPosttest Design. Dapat digambarkan sebagai berikut:

Pengukuruan $(\mathrm{O} 1) \longmapsto$ Manipulasi $(\mathrm{X})$

Pengukuran

Cooperative play sebagai intervensi dalam penelitian ini bertujuan untuk melatih dan meningkatkan kerjasama serta koordinasi antara kakak dan adik. Jenis permainan kooperatif yang digunakan adalah sebagai berikut:

- Menyusun balok bangunan

- Menyusun balok alat transportasi

- Puzzle gambar 1

- Puzzle gambar 2

- merangkai manik-manik kedalam tali dan membuat gelang untuk saudaranya.

- merangkai rantai kecil berdasarkan warna

- Merangkai rantai berdasarkan bentuk

- Lego

Intervensi dilakukan berdasarkan jenis permainan kooperatif tersebut. Instruksi dilakukan oleh peneliti langsung dan dibantu oleh 2 orang observer yang mengobservasi subjek partisipan dalam proses intervensi tersebut. Validitas intervensi akan diukur dengan expert judgment atau penilaian ahli yang kompeten di bidangnya. Penilaian ahli untuk intervensi ini akan dilakukan oleh ahli Psikolog Klinis Anak.

Selain menggunakan cooperative play, intervensi ini juga menggunakan alat ukur kuesioner dalam mengukur sibling rivalry. Alat ukur yang digunakan peneliti adalah skala baku Sibling Relationship Inventory (SRI) yang diadaptasi dari Boer et al. tahun 1997. Alasan peneliti menggunakan alat ukur ini adalah sesuai dengan rentang usia yang dibutuhkan yaitu 5 sampai dengan 12 tahun karena sesuai dengan usia subjek yaitu 5 tahun. Selain itu, alat ukur ini juga sudah dilakukan test-retest kepada 206 anak usia 6-12 dengan $\mathrm{p}<.001$ dan 452 anak lainnya diusia 5-12 tahun. SRI menggunakan 5 skala likert mulai dari 1, menunjukkan bahwa perilaku target "tidak pernah" terjadi hingga 5 menunjukkan perilaku target 'selalu' terjadi. Adapun system pengolahan data dilakukan dengan menggunakan SPSS.

Skala baku Sibling Relationship Inventory (SRI) yang diadaptasi dari Boer et al. tahun 1997, diantaranya:

1. Seberapa sering kakaknya mengurus atau menjaga adik kandungnya ketika tidak ada orang dewasa disekitarnya?

2. Kakak beradik kadang-kadang menimbulkan masalah atau memulai perkelahian atau berdebat satu sama lain, bahkan saat mereka saling mencintai/menyayangi. Seberapa sering kakaknya memulai perkelahian atau menimbulkan masalah bagi adik kandungnya?

3. Seberapa sering kakak terlihat marah pada adik kandungnya?

4. Beberapa anak berbagi rahasia dengan kakak beradik dan tidak pada anak-anak lain. Seberapa sering kakak berbagi rahasia dengan adik kandungnya?

5. Anak-anak kadang-kadang menyakiti kakak beradik mereka dengan cara mendorong dan memukul. Seberapa sering kakaknya melakukan hal-hal semacam ini kepada adik kandungnya?

6. Terkadang ada anak-anak yang berarti bagi kakak beradik, bahkan mereka benar-benar peduli. Seberapa sering kakak menggoda atau memanggil adik kandungnya?

7. Seberapa sering kakak memberikan bantuan kepada adik kandungnya?

8. Seberapa sering kakak meminta izin kepada adiknya ketika mengambil mainan milik adik kandungnya?

9. Seberapa banyak kakak membantu adik kandungnya dalam menemukan sesuatu?

10. Kebanyakan anak menyayangi kakak beradik, kadang-kadang meskipun mereka bertengkar di lain waktu. Seberapa sering kakak secara fisik memberikan sikap afeksi 
dengan adik kandungnya? (seperti memeluk, mencium, berpegangan tangan)

11. Banyak anak mengeluh bahwa ibu mereka tidak adil tentang bagaimana mereka memperlakukannya dibandingkan dengan bagaimana ibu mereka memperlakukan kakak beradik mereka. Seberapa sering kakak terlihat cemburu ketika ibu memperlakukan adik kandungnya yang lebih baik daripada memperlakukan kakaknya?

12. Seberapa sering kakaknya terlihat cemburu ketika ayahnya memperlakukan adik kandungnya lebih baik daripada memperlakukan kakak?

13. Seberapa banyak kakak terlihat mengagumi adik kandungnya seperti berpikir bahwa adiknya sangat spesial atau rapi?

14. Seberapa sering kakak berbagi dengan adik kandung ketika adiknya ingin bermain dengan kakaknya atau meminjam mainan kakaknya?

15. Bagaimana jika adik kandung terluka atau kesal, seberapa sering kakaknya mencoba membuat adik kandung merasa lebih baik?

16. Seberapa sering kakaknya terlihat merasa agak cemburu saat ayah memberikan perhatian atau kasih sayang kepada adik kandungnya?

17. Seberapa sering kakak merasa agak cemburu saat ibu memberikan perhatian atau kasih sayang terhadap adik kandungnya?

\section{Tahapan Pelaksanaan Intervensi}

Pelaksanaan intervensi dilakukan di rumah Subjek di salah satu perumahan cluster di wilayah Tangerang Selatan. Pelaksanaan intervensi diawali dengan memberikan Informed Consent kepada orang tua terkait kesediaan anaknya untuk diberikan intervensi Cooperative play, melakukan tahap interview berdasarkan lembar kuesioner yang ada, serta menggunakan lembar observasi yang digunakan untuk mengobservasi subjek penelitian selama kegiatan intervensi Cooperative Play berlangsung.
Adapun langkah-langkah dalam intervensi ini dijabarkan dalam bentuk tabel sebagai berikut:

Tabel 1. Persiapan Intervensi

\begin{tabular}{|c|c|c|c|}
\hline No. & Tahap-tahap & Alat / Media & Keterangan \\
\hline 1 & $\begin{array}{l}\text { Menyiapkan } \\
\text { Pretest dan } \\
\text { Postest }\end{array}$ & $\begin{array}{l}\text { Sibling } \\
\text { Relationship } \\
\text { Inventory } \\
\text { (SRI) }\end{array}$ & $\begin{array}{l}\text { Translasi dan } \\
\text { proses adaptasi } \\
\text { terhadap } 17 \text { item } \\
\text { pernyataan. }\end{array}$ \\
\hline 2. & $\begin{array}{l}\text { Melakukan } \\
\text { inform consent } \\
\text { kepada orang tua } \\
\text { subjek }\end{array}$ & $\begin{array}{l}\text { Surat/inform } \\
\text { consent dan } \\
\text { Alat tulis }\end{array}$ & $\begin{array}{l}\text { Proses } \\
\text { Persetujuan orang } \\
\text { tua subjek yang } \\
\text { ditunjukkan } \\
\text { dengan } \\
\text { menandatangani } \\
\text { inform consent } \\
\text { yang sudah } \\
\text { disepakati }\end{array}$ \\
\hline 3. & $\begin{array}{l}\text { Melakukan } \\
\text { wawancara } \\
\text { kepada orang tua } \\
\text { dan pengasuh } \\
\text { subjek dirumah } \\
\text { serta guru subjek } \\
\text { di Sekolah }\end{array}$ & $\begin{array}{l}\text { Panduan } \\
\text { wawancara }\end{array}$ & $\begin{array}{l}\text { Wawancara } \\
\text { dilakukan untuk } \\
\text { mengetahui } \\
\text { masalah yang } \\
\text { terjadi pada } \\
\text { subjek dan adik } \\
\text { kandungnya }\end{array}$ \\
\hline 4. & $\begin{array}{l}\text { Menentukan } \\
\text { media untuk } \\
\text { intervensi } \\
\text { cooperative play }\end{array}$ & $\begin{array}{l}\text { Balok } \\
\text { bangunan, } \\
\text { balok alat } \\
\text { transportasi, } \\
\text { Puzzle gambar } \\
\text { 1, Puzzle } \\
\text { gambar 2, } \\
\text { manik-manik, } \\
\text { rantai kecil } \\
\text { warna-warni, } \\
\text { rantai beragam } \\
\text { bentuk, dan } \\
\text { Lego }\end{array}$ & $\begin{array}{l}\text { Alat/media } \\
\text { cooperative play } \\
\text { akan dimainkan } \\
\text { oleh subjek } \\
\text { bersama dengan } \\
\text { adik kandungnya }\end{array}$ \\
\hline 5. & \begin{tabular}{l}
\multicolumn{2}{l}{ Memutuskan } \\
kedua orang \\
tuanya dan \\
pengasuh sebagai \\
observer dalam \\
proses intervensi
\end{tabular} & & $\begin{array}{lr}\begin{array}{l}\text { Kedua } \\
\text { dan }\end{array} & \text { pengang tua } \\
\text { sebagai } & \text { observer } \\
\text { yang } & \text { berfungsi } \\
\text { untuk } & \text { mencatat } \\
\text { hal-hal } & \text { yang } \\
\text { relevan rana } & \text { selama } \\
\text { proses } & \text { intervensi }\end{array}$ \\
\hline
\end{tabular}
intervensi.

\section{Pertemuan Ke:}

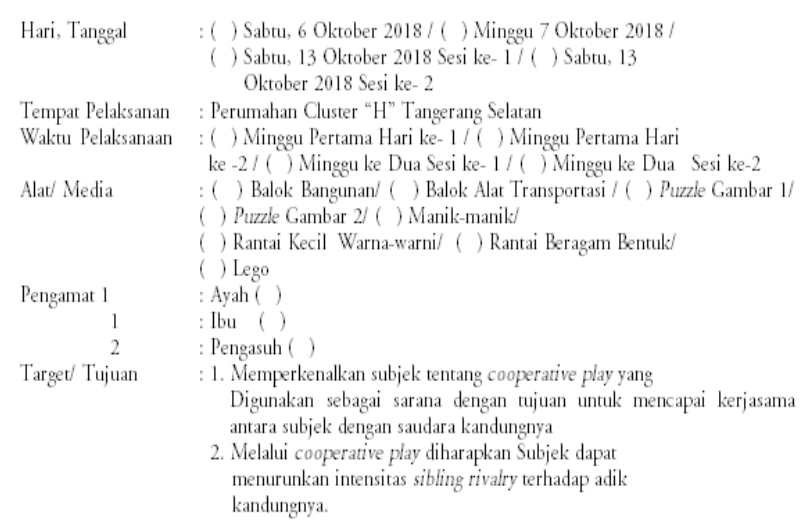


Jurnal Harkat : Media Komunikasi Gender, 15 (2), 2019

Rangkaian Aktivitas Intervensi terdiri dari:

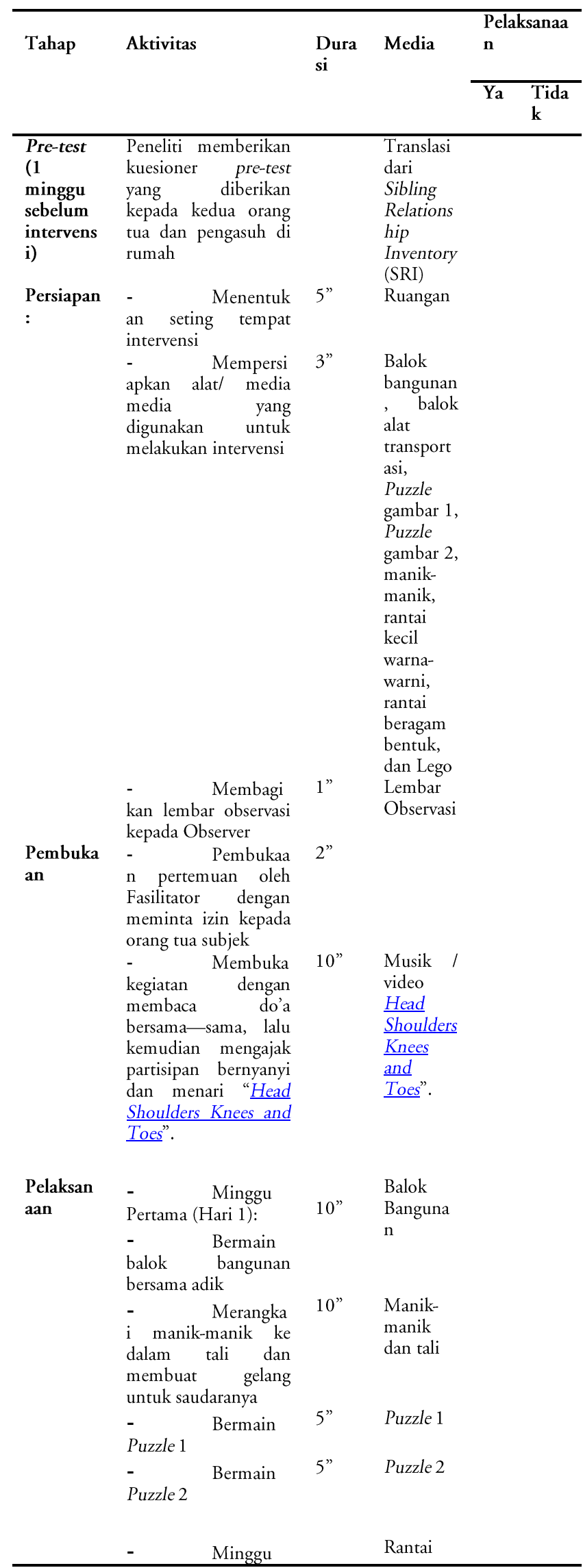

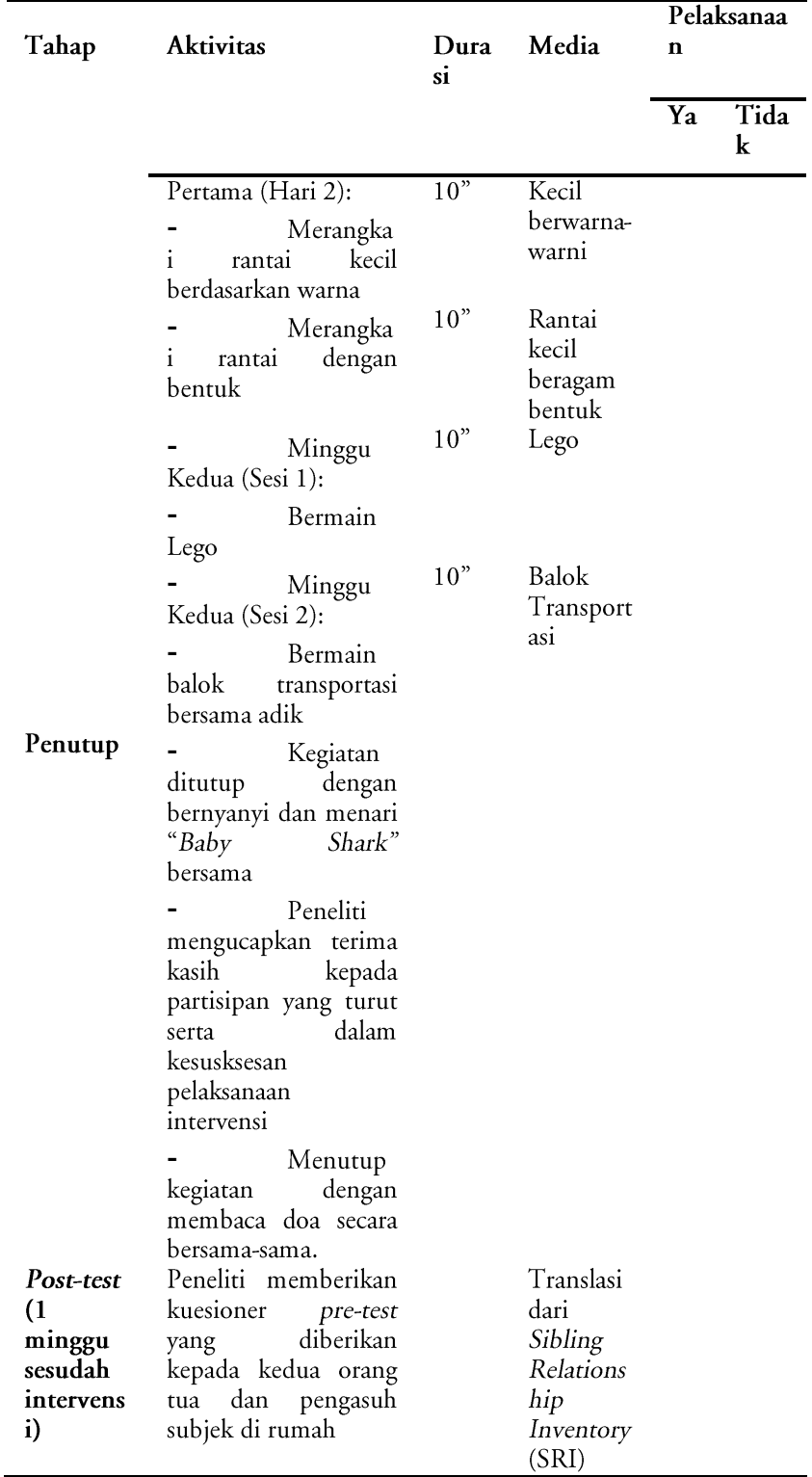

Catatan: Cecklist $(\sqrt{ })$ Jika Data maupun waktu sesuai dengan jadwal intervensi yang sudah ditentukan

Tabel 2: Isi intervensi

\begin{tabular}{|c|c|c|c|c|c|c|c|c|}
\hline \multicolumn{9}{|c|}{ Paired Samples Test } \\
\hline & \multicolumn{5}{|c|}{\begin{tabular}{|l} 
Paired Differences \\
\end{tabular}} & \multirow[t]{3}{*}{$\mathrm{t}$} & \multirow[t]{3}{*}{ Df } & \multirow{3}{*}{\begin{tabular}{|l}
$\begin{array}{l}\text { Sig. (2- } \\
\text { tailed) }\end{array}$ \\
\end{tabular}} \\
\hline & \multirow[t]{2}{*}{\begin{tabular}{|l} 
Mea \\
$\mathrm{n}$
\end{tabular}} & \multirow[t]{2}{*}{\begin{tabular}{|l} 
Std. \\
Deviati \\
on
\end{tabular}} & \multirow[t]{2}{*}{\begin{tabular}{|l} 
Std. \\
Error \\
Mean
\end{tabular}} & \multicolumn{2}{|c|}{$\begin{array}{l}95 \% \text { Confidence } \\
\text { Interval of the } \\
\text { Difference }\end{array}$} & & & \\
\hline & & & & Lower & Upper & & & \\
\hline $\begin{array}{lll}\mathrm{Pai} & \text { pretest } \\
\mathrm{r} 1 & \text { posttest }\end{array}$ & $\begin{array}{l}803 \\
92\end{array}$ & .95958 & .13437 & .53404 & 1.07381 & $\begin{array}{l}5.98 \\
3\end{array}$ & 50 & .000 \\
\hline
\end{tabular}

Setelah seluruh tahapan intervensi dilakukan, peneliti menutup pelaksanaan intervensi lalu kemudian dilanjutkan dengan melakukan pengolahan data pre-test dan posttest dengan menggunakan Microsoft office excel dan software computer berupa SPSS. Jika 
hasilnya uji T-test $<0.05$ pada skor post-test maka dapat disimpulkan bahwa intervensi cooperative play efektif dalam menurunkan Perilaku Sibling Rivalry.

\section{Hasil Intervensi}

Berdasarkan hasil program intervensi yang sudah dilakukan. Terlihat bahwa cooperative play memiliki peran dalam menurunkan perilaku sibling rivalry pada subjek terhadap saudara kandungnya. Hal ini ditunjukkan dengan hasil ujian SPSS melalui uji T-test pada uji significant (2-tailed) hasilnya adalah 0.000 yang artinya berpengaruh secara signifikan karena hasil uji signifikan menunjukkan lebih kecil dari $<0.05$ yang berarti bahwa ada perbedaan yang terjadi pada saat sebelum diberikan intervensi dan setelah diberikan intervensi. Selain itu, Mean menunjukkan hasil yang positive yaitu 0.80392 yang berarti bahwa adanya penurunan dalam perilaku sibling rivalry. Hal ini dapat dilihat pada tabel hasil pengolahan SPSS dibawah ini:

Tabel 3: hasil uji T-test

Paired Samples Statistics

\begin{tabular}{|ll|l|l|l|l|}
\hline & & Mean & N & $\begin{array}{l}\text { Std. } \\
\text { Deviation }\end{array}$ & $\begin{array}{l}\text { Std. Error } \\
\text { Mean }\end{array}$ \\
\hline \multirow{2}{*}{ Pair 1 } & pretest & 3.7451 & 51 & .97659 & .13675 \\
postest & 2.9412 & 51 & .92546 & .12959 \\
\hline
\end{tabular}

Adapun uji statistik yang menunjukkan penuruan perilaku sibling rivalry dapat dilihat pada tabel hasil pengolahan uji statistika melalui SPSS berikut ini:

Berdasarkan tabel tersebut dapat terlihat bahwa nilai Mean mengalami penurunan secara positif yang diartikan bahwa terjadi penurunan perilaku sibling rivalry pada Subjek. Sedangkan jika dilihat melalui diagram, penurunan perilaku sibling rivalry dapat dilihat sebagai berikut:

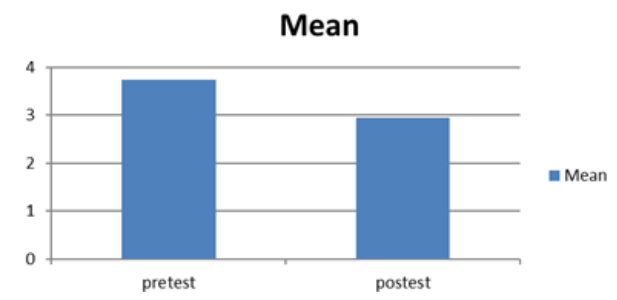

\section{Pembahasan}

Pada saat intervensi berlangsung, subjek pada awalnya terlihat kurang nyaman karena dikondisikan agar bermain bersama, ia terlihat enggan memberikan mainannya kepada adik kandungnya dan beberapa kali terjadi pertengkaran kecil. Namun setelah beberapa kali diarahkan, subjek semakin tampak terbiasa dengan situasi bermain bersama yang dinamakan cooperative play.

Diawali dengan permainan menyusun balok bangunan, menyusun balok alat transportasi, menyusun Puzzle gambar 1, Puzzle gambar 2, membuat gelang untuk saudara yang $t$ terbuat dari manik-manik, merangkai rantai kecil berdasarkan warna-warni, merengkai rantai berdasarkan bentuk, serta Lego.

Semua jenis media yang dijadikan sebagai bahan intervensi pada penelitian ini, hal yang paling lama subjek mainkan bersama adiknya adalah membangun balok bangunan, membangun balok transportasi, membuat gelang, serta Puzzle. Sedangkan merangkai rantai anak sudah terlihat agak bosan dan mengalami kesulitan dalam memasukkan satu rantai kepada rantai yang lain.

Selain itu, seminggu sebelum intervensi dilaksanakan, 3 orang yang terdekat dengan subjek mengisi kuesioner untuk mengetahui perkembangan perilaku anak sebelum diberikan intervensi dan sesudah diberikan intervensi. 3 orang terdekat tersebut sekaligus menjadi observer pada proses intervensi tersebut.

Berdasarkan kronologis kejadian dan gambaran proses intervensi di atas sehingga menghasilkan keefektifan cooperative play dalam menurunkan perilaku sibling sesuai dengan hasil penelitian yang dilakukan oleh Hasinuddin (tanpa tahun) bahwa permainan cooperative play berdampak signifikan terhadap perubahan perilaku sibling rivalry.

Maka berdasarkan hasil intervensi yang dilakukan dapat disimpulkan bahwa cooperative 
play efektif dalam menurunkan perilaku sibling rivalry.

\section{Penutup}

Proses intervensi dalam menurunkan perilaku sibling rivalry cukup membutuhkan waktu dalam mengondisikan subjek dan adik kandungnya agar bersikap baik selama intervensi. Namun faktor usia merupakan tantangan dan hambatan tersendiri. Sehingga membutuhkan persiapan dan energi lebih banyak.

Selain itu, saran untuk penelitian selanjutnya adalah sebaiknya dicoba menggunakan variabel lain selain cooperative play untuk menurunkan intensitas sibling rivalry seperti sosiodrama, pola asuh maupun variabel lainnya.

Selain itu proses penelitian belum maksimal menggandengkan teori-teori yang signifikan dalam hasil cooperative play dalam menurunkan sibling rivalry dikarenakan belum banyaknya penelitian dengan menggunakan metode intervensi ini. Oleh karena itu dengan adanya penelitian ini diharapkan dapat menambah literatur ilmiah intervensi efektifitas cooperative play dalam menurunkan sibling rivalry.

\section{Daftar Pustaka}

Boer, et al. (1997). The Factorial Structure of The Sibling Relationship Inventory (SRI) in American and Dutch Sample. Journal of Social and Personal Relationship Copyright (C) 1997 SAGE Publication (London, Thousand Oaks, $\mathrm{CA}$ and New Delhi) Vol 14 (6):851859.(0265-4075 (199712)14:6]

Hasinuddin. (-). Effect of Cooperative Play to sibling rivalry. 8th International Nursing Conference "Education, Practice And Research Development In Nursing"

Lecce, Serena. Et al (2011). Measuring the quality of the sibling relationship during middle childhood: The psychometric properties of the Sibling Relationship Inventory. European Journal Of Developmental Psychology 2011, 8 (4), 423-436
Maiorano, Michelle. (2010). A case study on sibling rivalry and the use of a social skills training model. Teses and Dissertations. 125. htp://rdw.rowan.edu/etd/125

Margaretha, Winda. (2016). Pengaruh Cooperative Play terhadap Sibling Rivalry pada Anak Sekolah Dasar. Universitas Kristen Satya Wacana Salatiga: Fakultas Psikologi.

Mize, Jacquelyn \& Ladd, Gary W. (1983). A Cognitive-Social Learning Model of Social-Skill Training. Department of Child Development and Family Studies, Purdue University. Psychological Review 1983, Vol.90, No. 2, 127-157

Safithry, Esty Aryani. (2016). Terapi Perilaku Untuk Mengurangi Perilaku Sibling Rivalry Pada Anak. Suluh Jurnal Bimbingan dan Konseling, April 2016, Volume 2 Nomor 2 (11-21) ISSN : 24607274.

Shaffer, D. R. (2014). Development psychology ninth edition childhood and adolescence. USA : Wadsworth Thomson Learning.

Spasojevic, et al. (2012). Brothers and Sisters at Play: Exploring Game Play with Siblings. USA: Seattle, Washington. CSCW'12, February 1115, 2012. Copyright 2012 ACM 978-1-4503$1086-4 / 12 / 02 \ldots \$ 10.00$.

Wong, Donna L. (2008). Pedoman Klinis Keperawatan Pediatrik. Jakarta: EGC 